\title{
Supporting strategic cultural change: the Strathclyde Learning Technology Initiative
} as a model

\author{
Allison Littlejohn* and Shona Cameron** \\ *Centre for Academic Practice, University of Strathclyde, \\ ***entre for Educational Systems, University of Strathclyde, \\ email: allison.littlejohn@strath.ac.uk
}

This paper describes the strategies being developed at the University of Strathclyde in response to the vision in the Dearing Report of a learning society in which Communication and Information Technology (C\&IT) is central to students' learning experiences. The Strathclyde Learning Technology Initiative aims to support strategic change in the development and use of new learning technologies to improve the quality and efficiency of teaching and learning within the University. In order for a major cultural shift in teaching and learning to take effect there are three main areas that need to be addressed: (i) many academics still work within a traditional teaching framework and believe that these methods can simply be transferred to the Web, (ii) students who have been taught in a traditional teaching environment need support in acquiring new learning skills for an electronic learning environment, and (iii) new methods of learning and teaching can only be successfully integrated within the environment of a supporting infrastructure and institutional climate. These key elements are further explored, drawing on the lessons learned from the implementation of the Initiative, and suggestions are made for ways of surmounting the barriers to the uptake of C\&IT perceived by academics.

\section{The future of higher education}

Higher education is in a period of great cultural change, accelerated by government recommendations (e.g. the Dearing Report), the introduction of tuition fees, implications arising from the National Grid for Learning and changes within secondary education (DfEE, 1997). More demands are being made on students to become independent, reflective learners. Much of this is coming from potential employers who are also requiring 
graduates to develop other personal transferable skills such as communication via new technologies (Harvey, Moon and Geal, 1997).

We recently asked a group of staff developers, 'How do you envisage teaching and learning in five years time?' Responses included: teaching and learning via centralized resources accessed by C\&IT, improved student access with fewer time barriers, increased emphasis on distance and open learning, less traditional and more active learning. All of these echo Dearing's vision of a connected learning society which 'opens up the possibility of higher education programmes being offered remotely by anyone anywhere in the world' (National Committee of Enquiry into Higher Education, 1997). In future students' learning and data management will focus on the use of a personal computer as the central tool. This computer will be used not only as a diary for timetabling, but also:

- as a means of communication (through email, text-based discussions, etc.);

- collaboration with tutors (through videoconferencing, shared whiteboards, etc.);

- data collection (via the WWW and specialist applications);

- report writing (via email, bulletin boards, and Web publishing);

- socializing (via email and videoconferencing etc.).

This new method of learning requires a significant cognitive transformation by both the student and teacher, a process requiring support by the university. If the potential of C\&IT to enhance learning is to be realized fully, staff and students need to receive appropriate training and support (DfEE, 1998).

The Dearing Report was hailed as a 'a blend of vision and realism' by the Committee of Vice-Chancellors and Principals of the Universities of the UK (CVCP, 1998). However, the reality of teaching and learning is that most academics have themselves been participants in a traditional teaching and learning environment and have limited conceptions about the use of the Internet for teaching and learning. Current literature highlights a major skills gap on the part of both teachers and learners which prevents the adoption of innovative teaching methods embracing C\&IT (Littlejohn and Sclater, 1998). Working effectively within an integrated online learning environment requires the development not only of practical IT skills, but also of pedagogical skills. Teachers and learners need to be supported in making the cognitive transformation from working within a traditional teaching and learning environment to active learning in a dynamic, integrated environment (Sosabowski, Herson and Loyd, 1998).

The Strathclyde Learning Technology Initiative aims to support cultural change in the adoption of new teaching and learning methodologies at the University of Strathclyde. The initiative is based upon the premise that this change is best brought about by supporting teachers and learners in both pedagogical and practical C\&IT skills. Also in order for a major cultural shift in teaching and learning to take effect, there are three main areas which need to be addressed: staff, student and infrastructure development. These three domains are inter-related. Neglecting one would have a detrimental effect on one or both of the others; therefore all three must be examined simultaneously. 


\section{Staff development}

The Dearing Report recommended that 'all institutions should review and update their staff development policies to ensure they address the changing roles of staff' (Recommendation 47). The response from bodies such as SEDA (Staff and Educational Development Association), which has done much to improve the status of staff development initiatives, was to welcome the emphasis 'on the contribution which staff development can and must make for a fully professionalised, accredited teaching force' (SEDA, 1997). Recent developments supporting staff in the use of C\&IT in teaching and learning at the University of Strathclyde include:

- a program of staff development workshops;

- two Masters level modules in a postgraduate certificate/diploma course for the accreditation of HE teaching: Advanced Academic Studies;

- the creation of a community of scholars using C\&IT for teaching;

- educational development with individual departments;

- the provision of a resource centre to help academics use learning technologies.

\section{Staff development programme}

In order to teach effectively in an online environment, academics must be given the opportunity to explore the differences (if any) between being an online tutor and using more traditional teaching methods. A recent study identifying staff resistance to computerbased teaching and learning recommended that change would best be accomplished by focused demand for lead staff training enabling staff to explore these issues. This training would not solely entail baseline IT training but would also change the perception of academics towards C\&IT as a teaching tool (Sosabowski et al., 1998). The Strathclyde staff development programme adopts this premise. The programme consists of a series of coherent workshops aimed primarily at staff with a teaching role. Each course blends current thinking on how to use technology effectively to enhance teaching and learning with practical training. The desired outcome is to inform staff of the potential C\&IT offers and to enable them to implement effectively new strategies for their own teaching and learning. These workshops include:

- Choosing the Right Technology;

- Electronic Assessment;

- Web-based Teaching;

- Electronic Libraries and;

- Internet Communication.

Full details of these courses can be found at http://cvu.strath.ac.uk/training/.

The Dearing Report recommended that staff should develop learning and teaching strategies which 'focus on the promotion of students' learning' (Recommendation 8). In the light of this recommendation the main focus of these workshops is in supporting staff in developing teaching and learning strategies which embrace C\&IT rather than on 
technological issues. Many academics still work within a traditional teaching framework and have limited insight into the fact that traditional teaching methods, such as a narrative style of lecturing, cannot simply be transferred onto the Web. Therefore staff developers recognize the fact that academics need to be fully immersed in the technology and to experience being in the role of a student. The result of transferring old teaching methodologies via new technology must be challenged (Ryan, 1998). During this staff development programme the pedagogical consequences of simply 'delivering lecture notes' via the Web are explored and staff are encouraged through the use of face-to-face and electronic discussions to think about ways of enhancing the student learning experience. Also information is offered on the various national and local services which are available to assist them.

Many participants have used the staff development programme as a springboard to adopting C\&IT in their courses and evaluation studies are currently in progress to determine the impact this programme has made on cultural change. Other support strategies include educational development with individual departments (Stefani, Littlejohn and Guerra, 1998) and the provision of a Multimedia Resource Centre offering computers, software and advice to academic or related staff. Efforts are also being made to develop a virtual community of scholars by running special events, such as seminars with invited speakers. However this has had limited impact since there is not yet a critical mass of lecturers at Strathclyde suitably equipped with the skills required to effect a major institution-wide shift in the teaching and learning culture of the university.

\section{Accredited programme}

A major strategic change within the University of Strathclyde was the development of a course for academic training of staff, in accordance with Dearing's Recommendation 13. A Postgraduate Certificate/Diploma course entitled 'Advanced Academic Studies' for academic and related staff for the purpose of accreditation of teaching and learning activities is now being offered. This course includes two optional modules at Scottish Masters level in 'Web-based Teaching' and 'Internet Communication'. These involve the design and creation of Web-based course material and provide the participant with the necessary skills for using the Web for teaching and learning. As well as hands-on workshops, the course includes a significant amount of online study and discussion of the pedagogical issues of using new technology to enhance teaching and learning. The modules blend pedagogical and practical skills. Learning via new technologies helps participants to develop new strategies for their teaching. Participants are placed in the role of online learners and are encouraged to exchange ideas to enable them to explore and experiment with working online. This view that academics must have the opportunity to experience the teaching and learning process within a safe environment is echoed by other staff developers (Ryan, 1998).

\section{Student development}

Students who have been taught in a traditional teaching environment need support in acquiring new learning skills to cope with an electronic learning environment. Recent efforts to enhance the student learning experience have focused on ensuring that students develop not only knowledge and understanding within a disciplinary context but also a range of personal transferable skills. Key skills highlighted in the Dearing Report include communication and the use of information technology (Recommendation 21). 


\section{Information literacy skills training programme}

Strathclyde University has taken a major step forward in introducing a training programme to support students in the development of personal transferable IT skills. The information literacy skills training programme for undergraduates aims to enable responsible and effective use of available technologies. This programme is being run in collaboration with the University of Glasgow, which has made attainment to an IT baseline level compulsory for all undergraduates (Martin, 1997).

The IT Induction Programme covers a range of basic computing skills: basic familiarity with graphical user interfaces, general housekeeping, using electronic mail, simple use of word processing and spreadsheets to using online library catalogues, and Internet searching. The programme has been delivered within the curriculum to first-year undergraduates in various academic departments, both by academic staff and by trained postgraduate tutors. There are several ways of reaching the IT skills baseline:

- A basic IT course is offered in six two-hourly sessions aimed at students with little experience of computers.

- An IT orientation course, incorporating four two-hourly sessions, is aimed at students with experience of using computers, but who are not necessarily familiar with the systems and software in common use in Higher Education.

- There is also an assessment-only route for skilled users of IT.

Ensuring that all students have basic IT skills means that departments can then progress further with the use of IT in the curriculum, concentrating on more advanced applications.

Learning support for students with disabilities

A recent HEFCE report (HEFCE, 1999) stresses the need to evaluate developments in IT and their impact on teaching regimes. This fully reiterates Dearing's recommendation to provide 'learning support for students with disabilities' (Recommendation 6). The appointment of a special needs technology support officer is allowing support for students with different types of disabilities via individual support and advice about adaptive technologies for personal study, hands-on workshops, drop-in sessions and special events. C\&IT is already playing an important role in ensuring that the university curriculum can be accessible to all potential students. The range of adaptive technologies available is continuing to expand and this, coupled with the development of appropriate courseware, enables those previously disadvantaged to consider university study.

In response to Dearing's recommendation to provide 'learning support for students with disabilities' (Recommendation 6), the university is widening access to the curriculum through the appointment of a special needs technology support officer. The aim is to support students with different types of disabilities via hands-on workshops, drop-in sessions, special events and individual support and advice about adaptive technologies for personal study. C\&IT is already playing an important role in ensuring that the university curriculum can be accessible to all potential students.

\section{Supporting students in developing new learning strategies}

Dearing's vision that C\&IT will be central to the student's learning experience requires the development of new learning strategies and wider student access to computers. Presently 
student support is offered in the form of a C\&IT Literacy Skills Programme which does not adequately address pedagogical and social requirements. In order to make the necessary cognitive transformation from being a traditional learner to learning within a fully integrated online learning environment students must be supported in developing new learning strategies. Pilot studies aimed at encouraging and supporting students in adopting new learning strategies and developing personal transferable skills are currently being developed. One interesting example of this was with students on an M.Sc. course in Energy Systems and the Environment. As part of their group projects students on this course were required to develop and maintain Project Management Logs using the Web as the key medium. Not only did this enable them to acquire the necessary IT skills to communicate via the Web, but they also developed additional personal transferable skills enabling them to work as reflective learners (Stefani et al., 1998). This initiative serves as a model for future teaching and learning. Clearly more emphasis in this area must be made and supported at the highest level within the institution and resources targeted towards developing an effective infrastructure.

\section{Infrastructure development}

In its report, the National Committee urges the design and use of materials which exploit the potential of C\&IT for innovation in learning. These new materials can only be successfully integrated within the environment of a supporting infrastructure and institutional climate. The communication of high-quality teaching materials via high-speed networks is essential to the realization of Dearing's vision. All the west of Scotland HEIs (Higher Education Institutions) are integral partners in the ClydeNet Metropolitan Area Network, a broadband network linking all the west of Scotland HE institutions. Now efforts are being made to create an integrated virtual learning environment to enable academics to exploit the potential of this broadband network for teaching and learning.

\section{Teaching and learning methodologies initiative}

As a result of a strategic review exercise in 1997, the University of Strathclyde decided to encourage the development of a wider range of teaching methods and materials. The Teaching and Learning Methodologies Initiative (TLMI, http://www.strath.ac.uk/ces/tlmi) represents a significant investment by the university to develop and implement innovative teaching methodologies across all faculties. All projects supported are using new communications technologies in various ways to enhance the traditional curriculum.

For example, the New Approaches to Teaching and Learning in Engineering (NATALIE) project has completely restructured the first year of a traditional mechanical engineering course consisting of lectures, labs and tutorials, into a new course given in an extensively refurbished lecture theatre, known as 'The Interactive Classroom'. This room is equipped with two classroom communication systems, one using graphics calculators and the other small handsets (similar to TV channel changers) which are infrared based. These technologies support the peer instruction approach to interactive teaching (Mazur, 1997) which concentrates on actively involving students in the learning process. During a teaching session, students are prompted to reflect on their comprehension of concepts in order to identify weaknesses in their understanding. This process of reflection aids in concept learning as well as encouraging discussion amongst students, leading to a better understanding overall (Davis, 1997): This form of collaborative learning facilitates group 
work, thereby equipping the students with transferable skills useful for future employment (Harvey et al., 1997). It also has the beneficial effect of helping them to settle into university life. It has been observed that students often interact within their assigned groups both academically and socially throughout the academic year.

Another of the TLMI projects is the Virtual Organizational Teaching Environment (VOTE), a major initiative within the Strathclyde Business School to promote the use of C\&IT to improve teaching and learning in business and management. The project centres on the development of a virtual online business environment which will form part of a core integrative curriculum supporting the development and acquisition of key skills in (Dearing Recommendation 21): communication, numeracy, use of IT, and learning how to learn.

The vision of the project is to revise the traditional undergraduate curriculum to incorporate a more radical pedagogical approach based on an interactive teaching game. The game features a virtual organization and encourages students to apply their knowledge to a variety of simulated real-world scenarios of varying complexity, supporting a range of pedagogical approaches from task-based to collaborative learning.

One major protlem in developing these online teaching materials is the lack of clarity of Internet copyright and intellectual property right issues (Macqueen, 1997). Therefore the TLMI projects are advised by an Internet copyright officer, appointed to co-ordinate copyright clearance for the use of third-party material in electronic resources used for teaching and learning within an integrated learning environment.

\section{Integrated Learning Environment - Clyde Virtual University}

The University of Strathclyde is committed to the development of an Integrated Learning Environment for teaching and assessment. This was achieved when the Clyde Virtual University (CVU http://cvu.strath.ac.uk/) was developed in 1995 as the first virtual university in Europe. CVU integrates the main components of a traditional university setting: lecture theatre, library, virtual café (for discussions), assessment hall and administration office. This model provides a series of tools enabling academics in the west of Scotland universities to create online learning packages, assessments, evaluations and discussion groups with little technical knowledge. The Clyde Virtual University model has been used extensively in the staff development programme as a framework on which academics can develop ideas for their own teaching. For example, in the course on Webbased Teaching, academics are given the opportunity to design their own teaching materials for the lecture theatre. They are encouraged to integrate electronic assessment, using the CVU assessment wizard, and discussion in the CVU café. This provides academics with hands-on experience of an Integrated Virtual Learning Environment, enabling them to assess perceived benefits and barriers to the successful adoption of C\&IT as a tool for teaching and learning.

\section{Perceived barriers to the adoption of C\&lT}

The use of C\&IT must have a significant value-added factor either in the quality of teaching and learning or in the efficiency with which academic staff can use their time. However, there is a fear amongst academics that the use of C\&IT has not yet reached the stage of being efficient (Ringle and Updegrove, 1998). There is therefore a reluctance among many 
academics to use technology in support of teaching and learning without an assurance of the long-term benefits by long-term evaluation studies (Harvey, 1998).

These sentiments were echoed during discussions at a course entitled 'Supporting Teaching and Learning - The IT Possibilities' for probationary lecturers from the Universities of Strathclyde, Glasgow and Paisley. As part of the course these lecturers were asked to consider individually the perceived barriers and success factors towards the adoption of C\&IT. The participants then discussed these issues in groups, in an effort to distil common factors. Each group was then asked to present the findings, which are listed in Table 1.

\begin{tabular}{|c|c|}
\hline Barriers to using C\&IT & Success factors \\
\hline - access to computing facilities & - keep students informed about courses \\
\hline $\begin{array}{l}\text { - cost and human resources required for } \\
\text { development } \\
\text { - not enough staff training available for using C\&IT }\end{array}$ & $\begin{array}{l}\text { - student involved in active leaming } \\
\text { - brings real world into teaching - especially in } \\
\text { concept leaming through simulations }\end{array}$ \\
\hline $\begin{array}{l}\text { - lack of proper integration into mainstream } \\
\text { teaching } \\
\text { - lack of diversity of educational resources }\end{array}$ & $\begin{array}{l}\text { - effective for distance learners } \\
\text { - self-paced leaming suits the new style of working } \\
\text { student }\end{array}$ \\
\hline $\begin{array}{l}\text { - courses may become stagnant if material is not } \\
\text { updated }\end{array}$ & $\begin{array}{l}\text { - access to a wealth of resources } \\
\text { - promotion of dialogue }\end{array}$ \\
\hline $\begin{array}{l}\text { - de-humanizing, often leading to lack of student } \\
\text { engagement }\end{array}$ & $\begin{array}{l}\text { - time efficiency using electronically marked } \\
\text { assessments }\end{array}$ \\
\hline $\begin{array}{l}\text { - some subjects more applicable to Web-based } \\
\text { teaching than others }\end{array}$ & · \\
\hline - verification of student identity during exams & \\
\hline
\end{tabular}

Table I: Barriers and success factors relating to the use of C\&IT

The main fears were related to a perceived lack of support in staff, student and infrastructure development. These concerns were addressed at the ALT-C98: conference participants were asked their views on these issues, with the aim of sharing potential solutions to drive forward the adoption of C\&IT in teaching and learning. Major concerns included the resources required to develop Web-based programmes: human resources, equipment resources and the amount of time required. A number of studies have echoed this concern that the initial time to set up a C\&IT course is high, though the required input may be reduced in the long term (Duffy, Arnold and Henderson, 1995). Despite the fact that many tools are being developed to save lecturers time, for example in assessment (for example Hunt, 1998; O'Hare, Mackenzie, O'Reilly and Wilkins, 1998) there is still a growing concern among academics as to the time required to gain the pedagogical skills to use these tools. Modelling online teaching and learning by placing academics in the role of an online learner during staff development programmes has been shown to be an effective way of overcoming this barrier (Ryan, 1998). 
Other concerns included the wide range of skills still required to create a Web-based course, despite the fact that these technologies are rapidly becoming more accessible. The response from participants at ALT-C was that specialist support should be available within institutions. This would aid the development of short courses which could be linked together, facilitating easy updating. The funding for development could be provided in the first instance by each institution or via grants with the understanding that savings or capital income would be made over time. Another suggestion was that there should be much more open sharing of resources, but perhaps this is at odds with the notion of creating an income from development. The effectiveness of staff training could be increased by setting up chains of peer tutoring (Cousin and Deepwell, 1998).

The problems of lack of diversity of educational resources, teaching material not being updated and lack of human contact are inherent in the traditional lecture-based HE system and are not necessarily particular to teaching via C\&IT. These problems are surmountable but concerted action is essential. These issues must be clarified by evaluation of the use of C\&IT in teaching and learning as a whole to quantify the added value of this approach.

\section{Summary}

Our research into perceived barriers to the adoption of C\&IT as a tool for teaching and learning illustrates that university teachers have a good understanding of the barriers to effective use of these technologies. Some of these barriers, such as lack of student engagement or the verification of student identity during exams, already exist within the traditional curriculum. Therefore our notions of course and curriculum design must be fully reviewed and revisited, focusing on communication, presentation, numeracy, problem solving and self-assessment skills. To enable the development of these higher-level skills using C\&IT it will be increasingly important to support students and academics in developing information literacy skills and applying these to teaching and learning scenarios.

To effect strategic cultural change, involving the integration of new technologies within the academic curriculum, the following issues have to be addressed (McCartan and Hare, 1996):

- commitment of support at the institutional level;

- development of an institutional strategy with related staff development;

- policies and programmes;

- provision for students and academic staff to acquire enabling IT skills.

Our findings fully support this work and acknowledge that there are still barriers to overcome, before adoption of appropriate technology-based applications in teaching, learning and assessment is commonplace. Further strategic change will require greater targeting of the limited resources available for staff and student training in order to enable wider implementation of new teaching and learning methodologies.' In the foreseeable future traditional lecture halls and computer laboratory space will merge as C\&IT becomes central to the students' learning experience. Hopefully the lessons learned from the 
implementation of the Strathclyde Learning Technology Initiative model can clarify future objectives in supporting strategic cultural change in UK Higher Education.

\section{References}

Cousin, G. and Deepwell, F. (1998), 'Virtual focus group techniques', Presentation at Evaluation of Learning Technology Conference,

http://www.edu.coventry.ac.uk/Taskforce/elt98pres/index.htm.

Committee of Vice-Chancellors and Principals of the Universities of the UK (1998), 'Implementing the new partnership', Review of Action,

http://www.cvcp.ac.ik/pubs/dear_acts.html.

Davis, E. A., Linn, M. C. and Clancy, M. J. (1995), 'Students' off-line and on-line experiences', Journal of Educational Computing Research, 12 (2), 109-34.

Department for Education and Employment (1997), 'Connecting the learning society: the government's consultation paper on the National Grid for Learning',

http://www.dfee,gov.uk/grid/consult/index.htm.

Department for Education and Employment (1998), 'Higher education for the twenty-first century: response to the Dearing Report',

http://www.lifelonglearning.co.uk/dearing/index.htm.

Duffy, C., Arnold, S. and Henderson, F. (1995), 'NetSem - electrifying undergraduate seminars', http://www.cti.ac.uk/publ/actlea/issue2/duffy/.

Harvey, J. (1998), 'LTDI: encouraging effective evaluations', Active Learning, 8, 62.

Harvey, L., Moon, S. and Geal, V. (1997), Graduate's Work: Organisational Change and Student's Attributes, Centre for Research into Quality and the Association of Graduate Recruiters: Birmingham.

HEFCE (1999), 'Guidance on base-level provision for disabled students in higher education institutions', Higher Education Funding Council for England Report 99/04', http://www.niss.ac.uk/education/hefce/pub99/99_04.html.

Hunt, N. (1998), 'Computer-aided assessment in statistics: the CAMPUS project', ALT-J, 6 (2), 58-67.

Littlejohn, A. and Sclater, N. (1998), 'Overcoming conceptual barriers to the use of Internet technology in university education', Proceedings of WebNet 98 , http://www.cvu.strath.ac.uk/admin/cvudocs/webnet/skills.html.

Martin, A. (1997), 'Student IT introduction: an evolving requirement', Active Learning 6, 42.

Mazur, E. (1997), Peer Instruction: A Users Manual, NJ: Prentice-Hall.

Macqueen, H. (1997), 'Copyright and the Internet', in Edwards, L. and Waelde, C. (eds.), Law and the Internet, Regulating Cyberspace, Hart Publications, 67-93.

McCartan, A. and Hare, C. (1996), 'Effecting institutional change: the impact of strategic issues on the use of IT', ALT-J, 4 (3), 21-8. 
National Committee of Inquiry into Higher Education (1997), Higher Education in the Learning Society, London.

O'Hare, D., Mackenzie, D., O'Reilly, C. and Wilkins, H. (1998), 'Application of TRIADS to the assessment of biology practicals', Proceeding of Computers in University Biology Conference - CUBE, http://www.liv.ac.uk/ctibiol/cube98/html/proceedings.html.

Ringle, M. and Updegrove, D. (1998), 'Is strategic planning for technology an oxymoron?', Cause/Effect, 21 (1), 18-23, http://www.educause.edu/ir/library/html/cem9814.html.

Ryan, M. (1998), 'Using computer mediated communication to deliver staff development', Active Learning, 9, 61-2.

Staff and Educational Development Association (1997), 'Dearing Committee Inquiry Report: Staff Development and Teacher Accreditation', Response to the National Committee Inquiry, http://www.seda.demon.co.uk/ncihe.html.

Sosabowski, M. H., Herson, K. and Loyd, A. W. (1998), 'Identifying and overcoming staff resistance to computer based teaching methods', Active Learning, 9, 26-30.

Stefani, L., Littlejohn, A. and Guerra, E. (1998), 'Encouraging reflective student learning: a case study', Student Wellbeing in $H E$, http://www.strath.ac.uk/Department/CAP/allison/wellbeing.html. 